\title{
Repetitive hyperpnoea causes peripheral airway obstruction and eosinophilia
}

\author{
M.S. Davis, A.N. Freed
}

Repetitive hyperpnoea causes peripheral airway obstruction and eosinophilia. M.S. Davis, A.N. Freed. (C) ERS Journal Ltd 1999.

ABSTRACT: Hyperpnoea of canine peripheral airways with dry air results in airway obstruction, mucosal damage, and inflammation. The purpose of this study was to evaluate the effect of repeated dry air challenge (DAC) on airway obstruction, reactivity and the development of airway inflammation in dogs.

Canine peripheral airways received DAC (delivered under general anaesthesia through a bronchoscope) every $48 \mathrm{~h}$ for two weeks. Peripheral airway resistance and reactivity were measured prior to each DAC. After the final DAC, bronchoalveolar lavage fluid (BALF) cells and soluble mediators from challenged and control airways were measured.

Repeated bronchoscopy had no effect on airway mechanics. Repeated DAC produced cumulative increases in peripheral airway resistance and peak obstructive response to DAC. The response to hypocapnia was also increased in airways receiving repeated DAC. However, when the response to agonists was expressed as a change from baseline, consistent significant increases were not observed. Repeated bronchoscopy produced insignificant changes in BALF cells and eicosanoid mediators. Repeated DAC produced marked eosinophilic inflammation and increased prostaglandins $D_{2}, E_{2}$, and $F_{2 \alpha}$, as well as leukotrienes $C_{4}-E_{4}$.

In conclusion, repeated dry air challenge in dogs in vivo causes persistent airway obstruction and inflammation not unlike that found in human asthma.

Eur Respir J 1999; 14: 57-62.

Epidemiological studies reveal an increased incidence of asthma in winter sport athletes who routinely experience hyperpnoea during training under frigid conditions [1-5]. In one study, $\sim 80 \%$ of the athletes exhibited asthma or asthma-like symptoms, compared with only $3 \%$ of a reference population [2]. These symptoms persisted throughout the warmer months in these individuals. The authors of this study have suggested that repeated episodes of hyperpnoea with cold air may predispose subjects to the development of asthma.

The acute effects of hyperpnoea on airway function have been well documented. Hyperpnoea with frigid air is known to cause peripheral airway cooling in both normal and asthmatic subjects [6-8]. In asthmatic subjects, transient airway obstruction occurs after hyperpnoea (hyperpnoea-induced bronchoconstriction; HIB) [6]. A canine model of HIB has been developed to investigate mechanisms that may be involved in exercise-induced asthma [9]. In this model, room temperature dry air is delivered at high flow rates through a bronchoscope into a wedged sublobar segment (dry air challenge; DAC). This manipulation produces the same thermal profile (presumably due to the same degree of evaporative cooling) as that produced at the same segmental level in humans hyperventilating with frigid air [7, 10]. Similarities between hyperventilation with frigid air in humans and DAC in the canine model extend to the timing of both the early [9] and late phase obstruction $[11,12]$, as well as the cellular
Dept of Environmental Health Sciences, The Johns Hopkins University, Baltimore, MD, USA

Correspondence: A.N. Freed, Division of Physiology; 7006 SHPH, The Johns Hopkins University, 615 North Wolfe Street, Baltimore, Maryland 21205, USA. Fax: 4109550299

Keywords: Airway hyperreactivity asthma

$\operatorname{dog}$

eosinophilia

hyperpnoea

Received: April 231998

Accepted after revision December 181998

This work was supported by the National Institutes of Health Grants HL51930, HL07534, and ES03819. and lipid mediator changes observed in the post-challenge bronchoalveolar lavage fluid (BALF) [11, 13, 14].

Based on the epidemiological studies in winter sport athletes [1-5], it was hypothesized that repeated hyperpnoea with dry air causes chronic airway inflammation and airway obstruction. To test this hypothesis, the cumulative effects of repeated DAC on peripheral airway mechanics and inflammation were examined in a canine model of cold air hyperpnoea.

\section{Material and methods}

\section{Study design}

In each dog, three airways in separate lobes were wedged with a bronchoscope on the first day of the protocol. The location of the wedged bronchoscope was recorded in each airway by constructing a map of the proximal airway branches leading to the wedge site. Using this map, the bronchoscope could be advanced on subsequent days to the same wedge site. Two mapped airways in each dog were designated repeated challenge airways (repeated DAC). In one airway, peripheral airway resistance $(R \mathrm{pa})$ and maximal peripheral airway resistance to hypocapnia $\left(R\right.$ pa,max, $\left.\mathrm{CO}_{2}\right)$ were measured prior to DAC $(\mathrm{n}=6)$. In the second airway, only $R$ pa was measured prior to DAC $(n=5)$. The third mapped airway served as the control for the repeated wedging of the bronchoscope (repeated wedge), and only $R \mathrm{pa}$ and $R \mathrm{pa}, \mathrm{max}, \mathrm{CO}_{2}$ were 
measured $(n=6)$. DAC was not performed in this airway. The experimental protocol was repeated on the same airways every $48 \mathrm{~h}$ for 2 weeks, for a total of eight DACs per challenged airway. On the final day, the three principal airways and a fourth airway were lavaged. BALF from the fourth airway (control) represented a baseline for the effects of repeated anaesthesia, and served as a control for the effect of repeated bronchoscopy.

Because a single DAC is known to cause changes in BALF cells and eicosanoids, the BALF from repeated DAC airways was compared with BALF obtained $10 \mathrm{~min}$ after a single DAC in a naive airway (single DAC) $(n=10)$. Recovered BALF was analysed in a manner identical to that used for the BALF recovered from other airways. Results from the analysis of BALF from single DAC airways were compared to results from repeated DAC airways to differentiate between changes caused by the most recent DAC and those present as a result of the repeated DAC.

\section{Methods}

All animals were handled and maintained in accordance with the Policy and Procedures Manual published by the Johns Hopkins University School of Hygiene and Public Health's Animal Care and Use Committee (ACUC). The ACUC is sanctioned by the American Association of Accreditation for Laboratory Animal Care.

Measurement of peripheral airway resistance. Male mongrel dogs were anaesthetized with an intravenous bolus of thiopental $\left(25 \mathrm{mg} \cdot \mathrm{kg}\right.$ bodyweight $\left.\mathrm{t}^{-1}\right)$ and fentanyl $(1 \mu \mathrm{g} \cdot \mathrm{kg}$ bodyweight $\left.{ }^{-1}\right)$, and maintained under anaesthesia with additional intravenous boluses of fentanyl $(1 \mu \mathrm{g} \cdot \mathrm{kg}$ bodyweight $^{-1}$ ) every $15 \mathrm{~min}$. The depth of anaesthesia was assessed by heart rate, blood pressure, canthal reflex, and the presence of spontaneous movements and breathing. Dogs were intubated and mechanically ventilated $(17 \mathrm{~mL} \cdot \mathrm{kg}$ bodyweight ${ }^{-1}$ ) with room air. End-tidal $\mathrm{CO}_{2}$ was monitored with a $\mathrm{CO}_{2}$ analyser (Beckman LB-2; Beckman Inc., Anaheim, CA, USA) and maintained at $\sim 4.5 \%$ by adjusting ventilator frequency. Heart rate and blood pressure were monitored via a noninvasive monitor (Datascope Accutorr 1A; Datascope Corp., Paramus, NJ, USA), and rectal temperature was monitored using a telethermometer (Yellow Springs Instrument Co., Yellow Spring, OH, USA). A bronchoscope (Olympus BF Type P10; Olympus Corp. of America, New Hyde Park, NY, USA, 5 mm o.d.) was inserted through an airtight portal of the endotracheal tube and gently wedged into a sublobar segmental bronchus. The suction port $(1.2 \mathrm{~mm})$ of the bronchoscope was connected to a pressure transducer (Statham, Gould Inc., Oxnard, CA, USA) which was used to measure airway pressure in the subtended lung segment $\left(P_{\text {sls }}\right)$. Compressed, dry, room temperature, $5 \% \mathrm{CO}_{2}$ in air was delivered at a rate of $200 \mathrm{~mL} \cdot \mathrm{min}^{-1}$ through the suction port of the bronchoscope into the wedged sublobar segment. $R$ pa was measured by stopping the ventilator during exhalation, such that the unobstructed areas of the lung equilibrated with atmospheric pressure at functional residual capacity. Under these conditions, $P$ sls decays to a plateau at a pressure greater than the alveolar pressure (atmospheric) in the surrounding unobstructed lung so that $R \mathrm{pa}=P_{\mathrm{sls}} / 200 \mathrm{~mL} \cdot \mathrm{min}^{-1}$.
Airway reactivity to hypocapnia. To assess nonspecific airway reactivity, insufflation of dry $5 \% \mathrm{CO}_{2}$ in air was switched to $0 \% \mathrm{CO}_{2}$ at $200 \mathrm{~mL} \cdot \mathrm{min}^{-1}$ for $3 \mathrm{~min}$. Reactivity was recorded as the peak $R \mathrm{pa}$ at the end of the 3 min challenge $\left(R \mathrm{pa}, \mathrm{max}, \mathrm{CO}_{2}\right)$ and the peak change from baseline $R$ pa $\left(\Delta R\right.$ pa,max, $\left.\mathrm{CO}_{2}\right)$.

Dry air challenge. DAC was performed by increasing the insufflation of dry $5 \% \mathrm{CO}_{2}$ in air from 200 to 2,000 $\mathrm{mL} \cdot \mathrm{min}^{-1}$ for $5 \mathrm{~min}$. Airflow was then returned to 200 $\mathrm{mL} \cdot \mathrm{min}^{-1}$ and $R$ pa was monitored over the next $15 \mathrm{~min}$. Reactivity to DAC was recorded as the peak $R$ pa recorded after the challenge $(R \mathrm{pa}, \mathrm{max}, \mathrm{DAC})$ and the peak change from baseline $R$ pa $(\Delta R \mathrm{pa}, \mathrm{max}, \mathrm{DAC})$.

Bronchoalveolar lavage fluid recovery and analysis. Three 20-mL aliquots of warmed Hanks' buffered saline were infused through the bronchoscope into the wedged sublobar segment, and then recovered by gentle aspiration. The recovered fluid was pooled and the volume determined. Nucleated cells were counted using a haemacytometer, and cytocentrifuged cells stained with a modified Wright-Giemsa stain were used for differential counts of nucleated cells. The remainder of the sample was centrifuged, and the supernatant was passed through a C-18 Sep-Pak exchange cartridge (Waters Corp., Milford, MA, USA) and eluted with $4 \mathrm{~mL}$ methanol. Aliquots of the eluted sample were dried under vacuum, reconstituted with buffered saline, and analysed using commercially available enzyme-linked immunosorbent assay (ELISA) kits for thromboxane $(\mathrm{Tx}) \mathrm{B}_{2}$, prostaglandin $(\mathrm{PG}) \mathrm{E}_{2}, \mathrm{PGF}_{2 \alpha}$ (Neogen Inc., Lexington, KY, USA), and $\mathrm{PGD}_{2}$ (Cayman Chemical Inc., Ann Arbor, MI, USA), and sulphidopeptide leukotrienes $\mathrm{C}_{4}-\mathrm{E}_{4}$ (Neogen Inc.).

\section{Analysis}

$R$ pa, $R$ pa,max, $\mathrm{CO}_{2}$ and $R$ pa,max,DAC data were analysed using the Friedman repeated measures analysis of variance (ANOVA). The Student-Newman-Keuls test applied to ranks was used to compare individual treatment means. The Mann-Whitney rank sum test was used to compare BALF cellular and biochemical data. Statistical significance in all cases was judged at $p<0.05$. All values are expressed as the mean \pm SEM.

\section{Results}

\section{Baseline Rpa}

Repeated DAC of canine peripheral airways increased baseline $R$ pa, whereas repeated wedging did not significantly alter baseline $R$ pa (fig. 1 ). Baseline $R$ pa on day 1 was $0.80 \pm 0.13 \mathrm{cmH}_{2} \mathrm{O} \cdot \mathrm{mL}^{-1} \cdot \mathrm{s}$ in the repeated wedge airways $(n=6)$, which was similar to that in the repeated DAC airways on day $1\left(0.80 \pm 0.079 \mathrm{cmH}_{2} \mathrm{O} \cdot \mathrm{mL}^{-1} \cdot \mathrm{s}, 11\right.$ airways in six dogs). Baseline $R$ pa of repeated wedge airways did not significantly change throughout the duration of the experiment $(\mathrm{p}=0.659)$. However, in repeated DAC airways base-line $R$ pa increased with repeated challenge (fig. $1 ; \mathrm{p}=0.033$ ). Baseline $R \mathrm{pa}$ was significantly higher on days $9\left(1.24 \pm 0.19 \mathrm{cmH}_{2} \mathrm{O} \cdot \mathrm{mL}^{-1} \cdot \mathrm{s}\right), 11(1.29 \pm 0.25$ $\left.\mathrm{cmH}_{2} \mathrm{O} \cdot \mathrm{mL}^{-1} \cdot \mathrm{s}\right), 13\left(1.26 \pm 0.23 \mathrm{~cm} \mathrm{H} \mathrm{H}_{2} \mathrm{O} \cdot \mathrm{mL}^{-1} \cdot \mathrm{s}\right)$, and 15 $\left(1.29 \pm 0.22 \mathrm{cmH}_{2} \mathrm{O} \cdot \mathrm{mL}^{-1} \cdot \mathrm{s}\right)$, when compared with day 1 $\left(0.80 \pm 0.08 \mathrm{cmH}_{2} \mathrm{O} \cdot \mathrm{mL}^{-1} \cdot \mathrm{s}\right)$. 


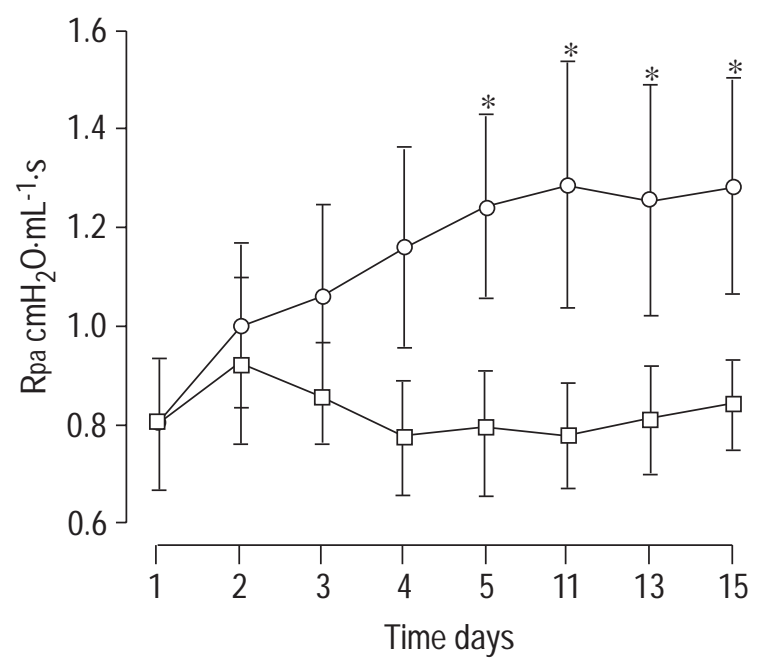

Fig. 1. - Baseline peripheral airways resistance $(R \mathrm{pa})$ in repeated wedge $(\square ; n=6)$ and repeated dry air challenge $(O ; n=6)$ airway of the dogs. Data are expressed as mean \pm SEM. ${ }^{*}: \mathrm{p}<0.05$, compared to day 1 .

\section{Peripheral airway reactivity to hypocapnia}

Peak airway response to hypocapnia tended to increase with repeated DAC, but this increase was not significant in either repeated wedge or repeated DAC airways. However, the change in maximal $R$ pa $(\Delta R$ pa,max $)$ from baseline in response to hypocapnia was significantly greater in repeated DAC airways. In repeated wedge lobes, $R$ pa,max, $\mathrm{CO}_{2}$ on day 1 was $2.85 \pm 0.33 \mathrm{cmH}_{2} \mathrm{O} \cdot \mathrm{mL}^{-1} \cdot \mathrm{s}$, and neither $R$ pa,max, $\mathrm{CO}_{2}$ nor $\Delta R$ pa,max, $\mathrm{CO}_{2}$ changed over the duration of the experiment ( $\mathrm{p}=0.566$ ) (fig. 2). $R$ pa,max, $\mathrm{CO}_{2}$ in repeated $\mathrm{DAC}$ lobes was $3.04 \pm 0.52 \mathrm{cmH}_{2} \mathrm{O} \cdot \mathrm{mL}^{-1} \cdot \mathrm{s}(\mathrm{n}=6)$ on day 1 . Though $R$ pa,max, $\mathrm{CO}_{2}$ tended to increase with repeated challenge, this was not significant $(\mathrm{p}=0.099)$ (fig. 2a). However, $R$ pa,max, $\mathrm{CO}_{2}$ in the repeated DAC lobes was significantly higher on day $9\left(3.29 \pm 0.68 \mathrm{cmH}_{2} \mathrm{O} \cdot \mathrm{mL}^{-1} \cdot \mathrm{s}\right)$ than day $1\left(2.18 \pm 0.40 \mathrm{cmH}_{2} \mathrm{O} \cdot \mathrm{mL}^{-1} \cdot \mathrm{s}, \mathrm{p}=0.034\right)$.

\section{Reactivity to repeated $D A C$}

Repeated DAC of peripheral airways resulted in an increase in the peak response to DAC. Rpa,max,DAC on day 1 was $1.77 \pm 0.27 \mathrm{cmH}_{2} \mathrm{O} \cdot \mathrm{mL}^{-1} \cdot \mathrm{s}(11$ airways in six dogs). $R$ pa,max,DAC increased with repeated challenge $(\mathrm{p}=0.0134)$, and was significantly higher than day 1 , on days $3(2.14 \pm$ $\left.0.34 \mathrm{cmH}_{2} \mathrm{O} \cdot \mathrm{mL}^{-1} \cdot \mathrm{s}\right), 9\left(2.31 \pm 0.40 \mathrm{cmH}_{2} \mathrm{O} \cdot \mathrm{mL}^{-1} \cdot \mathrm{s}\right), 11$ $\left(2.40 \pm 0.46 \mathrm{cmH}_{2} \mathrm{O} \cdot \mathrm{mL}^{-1} \cdot \mathrm{s}\right), 13\left(2.26 \pm 0.39 \mathrm{cmH}_{2} \mathrm{O} \cdot \mathrm{mL}^{-1} \cdot \mathrm{s}\right)$, and $15\left(2.54 \pm 0.45 \mathrm{cmH}_{2} \mathrm{O} \cdot \mathrm{mL}^{-1} \cdot \mathrm{s}\right)($ fig. $3 \mathrm{a}) . \Delta R \mathrm{pa}$,max,DAC did not change over the duration of the experiments (fig 3b).

Effects of repeated bronchoscopy on BALF cell and mediator profiles

Repeated bronchoscopy had few effects on BALF cell and mediator profiles. Macrophage concentrations were higher in control $\left(53.12 \pm 12.22\right.$ cells $\left.\cdot \mathrm{mL}^{-1}\right)$ than repeated wedge lobes $\left(24.51 \pm 6.53\right.$ cells $\left.\cdot \mathrm{mL}^{-1} ; \mathrm{p}=0.044\right)$ (fig. $4 \mathrm{a}$ ). $\mathrm{PGF}_{2 \alpha}$ concentrations were also higher in control BALF $\left(36.00 \pm 7.63 \mathrm{pg} \cdot \mathrm{mL}^{-1}\right)$ compared to repeated wedge BALF $\left(21.10 \pm 5.51 \mathrm{pg} \cdot \mathrm{mL}^{-1} ; \mathrm{p}=0.044\right)$ (fig. 5a). There were no other significant differences between control and repeated wedge BALF cells or mediators.
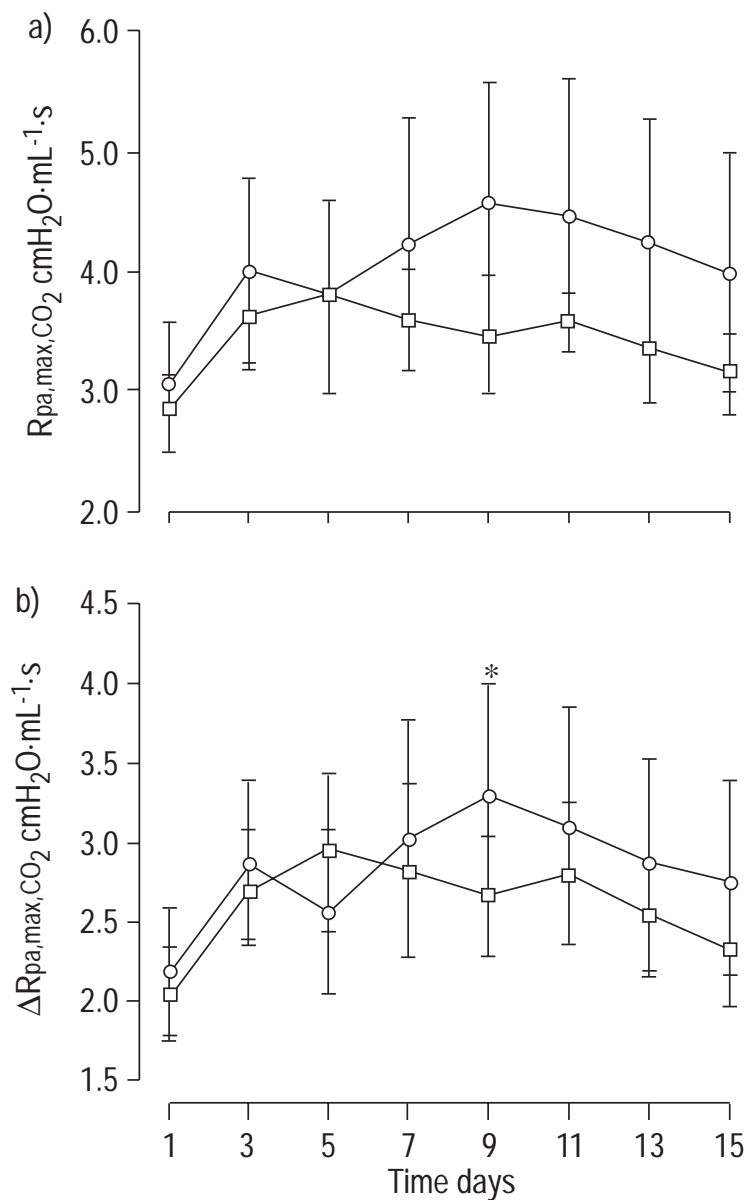

Fig. 2. - Hypocapnic reactivity in reaped wedge $(\square ; n=6)$ and repeated dry air challenge $(O ; n=6)$ of dogs. a) Peak peripheral airways resistance after hypocapnic challenge $\left(R\right.$ pa,max, $\left.\mathrm{CO}_{2}\right)$; and $\left.\mathrm{b}\right)$ Peak change from baseline resistance after hypocapnic challenge $\left(\Delta R\right.$ pa,max, $\left.\mathrm{CO}_{2}\right)$. Data are presented as mean \pm SEM. ${ }^{*}: \mathrm{p}<0.05$, compared with day 1 .

\section{Effects of repeated DAC on BALF cell and mediator profiles}

Repeated DAC resulted in granulocytic airway inflammation when compared with repeated bronchoscopy without DAC. Neutrophils (repeated DAC 6.79 $\pm 2.11 \times 10^{4}$ cells $\cdot \mathrm{mL}^{-1}$, repeated wedge $1.63 \pm 0.91 \times 10^{4}$ cells $\cdot \mathrm{mL}^{-1}$; $\mathrm{p}=0.045$ ), eosinophils (repeated DAC $17.69 \pm 4.95$ cells. $\mathrm{mL}^{-1}$, repeated wedge $2.20 \pm 0.77 \times 10^{4}$ cells $\cdot \mathrm{mL}^{-1} ; \mathrm{p}=$ 0.011 ), and epithelial cells (repeated DAC $1.27 \pm 0.43$ cells $\cdot \mathrm{mL}^{-1}$, repeated wedge $0.08 \pm 0.08 \times 10^{4}$ cells $\cdot \mathrm{mL}^{-1}$; $\mathrm{p}=0.011$ ) were increased in BALF recovered from repeated DAC airways when compared to the repeated wedge BALF (fig. 4b). Compared to the repeated wedge, BALF from repeated DAC lobes contained greater concentrations of leukotrienes (repeated DAC $101.13 \pm 23.50 \mathrm{pg} \cdot \mathrm{mL}^{-1}$, repeated wedge $\left.7.52 \pm 3.44 \mathrm{pg} \cdot \mathrm{mL}^{-1} ; \mathrm{p}=0.001\right), \mathrm{PGD}_{2}$ (repeated DAC $604.25 \pm 312.76 \mathrm{ng} \cdot \mathrm{mL}^{-1}$, repeated wedge $20.98 \pm 12.59 \mathrm{pg} \cdot \mathrm{mL}^{-1} ; \mathrm{p}=0.002$ ), $\mathrm{PGE}_{2}$ (repeated DAC $50.91 \pm 5.25 \mathrm{pg} \cdot \mathrm{mL}^{-1}$, repeated wedge $30.01 \pm 6.10 \mathrm{pg} \cdot \mathrm{mL}^{-1}$; $\mathrm{p}=0.011$ ), and $\mathrm{PGF}_{2 \alpha}$ (repeated DAC $184.76 \pm 36.05 \mathrm{pg}$. $\mathrm{mL}^{-1}$, repeated wedge $21.10 \pm 5.51 \mathrm{pg} \cdot \mathrm{mL}^{-1} ; \mathrm{p}=0.008$ ) (fig. $5 b)$. BALF from repeated DAC airways had significantly higher concentrations of neutrophils $(p<0.001)$ and eosinophils $(\mathrm{p}<0.001)$ when compared with BALF from single 

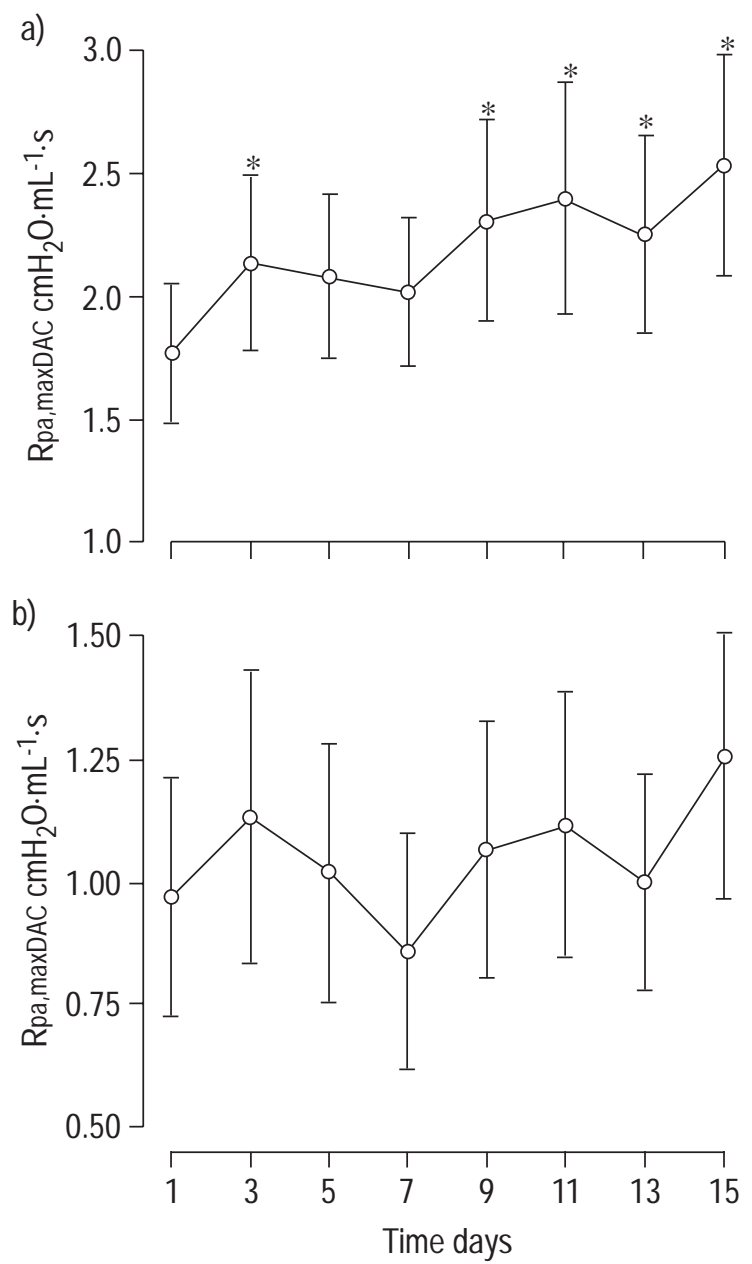

Fig. 3. - Reactivity to dry air (DAC) in repeated DAC airways (11 lobes in six dogs). Data are expressed as mean \pm SEM. a) peak peripheral airways resistance after DAC (Rpa,max,DAC); and $\mathrm{b})$ peak change from baseline resistance after DAC $\left(R\right.$ pa,max,DAC). ${ }^{*}: \mathrm{p}<0.05$, compared with day 1.

DAC airways (fig. 4c). However, BALF from repeated DAC airways had significantly less $\mathrm{PGE}_{2}(\mathrm{p}=0.038)$ and $\mathrm{PGF}_{2 \alpha}(\mathrm{p}=0.0073)$ when compared with BALF from single DAC airways (fig. 5c).

\section{Discussion}

This study demonstrates that dry air challenge repeated every $48 \mathrm{~h}$ increases $R$ pa. Baseline $R$ pa in repeated wedge airways remained remarkably constant. In contrast, repeated DAC resulted in marked increases in baseline $R$ pa. These increases in baseline $R$ pa developed gradually, and were not significantly different from the initial baseline until day 9 of this study (fig. 1). Rpa appeared to plateau at that point, suggesting that additional DAC would not result in greater obstruction. Whether the existing obstruction was caused by increased tonic activity of the smooth muscle, mucosal thickening, or intraluminal debris (e.g., mucus or exudate) or a combination of these factors could not be determined from this study, but speculation based on the results of these reactivity and BALF analysis will be made later in the discussion.

Peak response to hypocapnia did not change during the two week protocol in either repeated wedge or repeated DAC airways (fig. 2a). $\Delta R$ pa,max, $\mathrm{CO}_{2}$ in repeated DAC a)
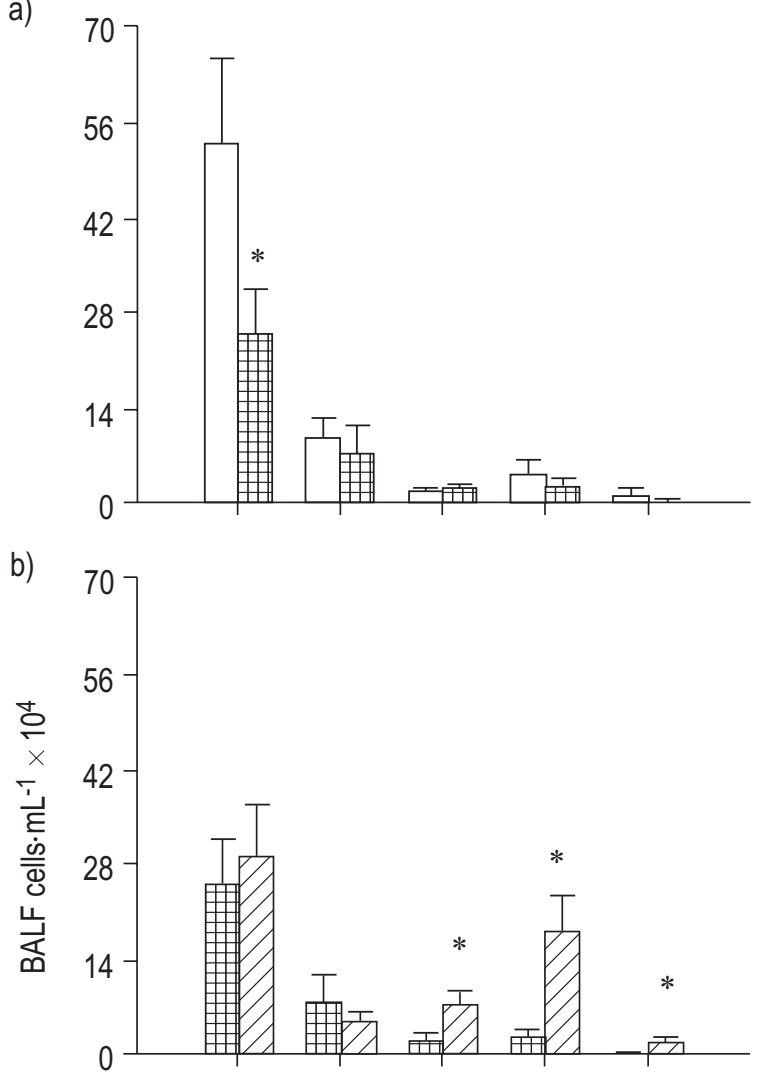

c)

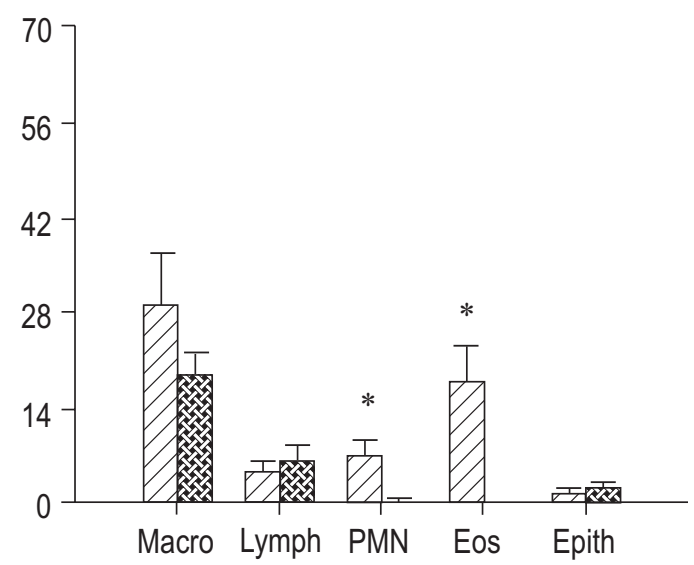

Fig. 4. - Bronchoalveolar lavage fluid (BALF) nucleated cell concentrations (mean \pm SEM) from: a) control $(\square ; n=6)$ and repeated wedge (曲; $n-6)$; b) repeated wedge and repeated dry air challenge (DAC) $(\mathbb{Z} ; \mathrm{n}=10)$; and c) repeated DAC and single DAC (网; $n=10$ ) airways. Macro: macrophages; lymph: lymphocytes; PMN: polymorphonuclear cells; Eos: eosinophils; Epith: epitheloid cells. ${ }^{*}: \mathrm{p}<0.05$, significantly different from graph pair.

airways was increased on day 9 (fig. 2b), but its transient nature calls into question the physiological relevance of this observation. Hypocapnia is believed to cause smooth muscle constriction by increasing the intracellular $\mathrm{pH}$ of the myocyte [15]. Additionally, thickening of the airway wall or intraluminal debris would serve to amplify normal smooth muscle constriction. The fact that minimal increases in reactivity to hypocapnia were measured, suggests that airway structural or intraluminal changes play a small role in the mechanical changes in this model. 
a)

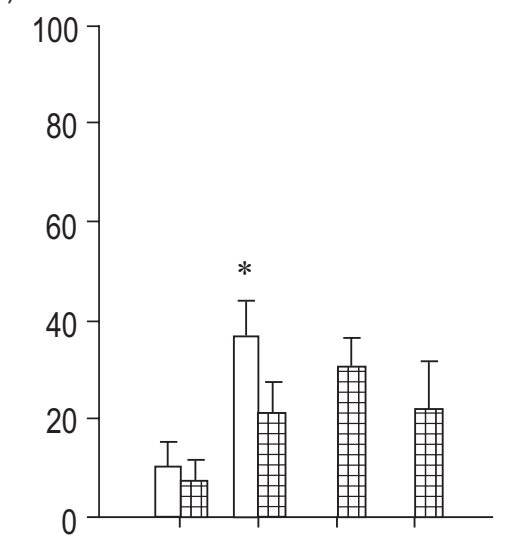

b)

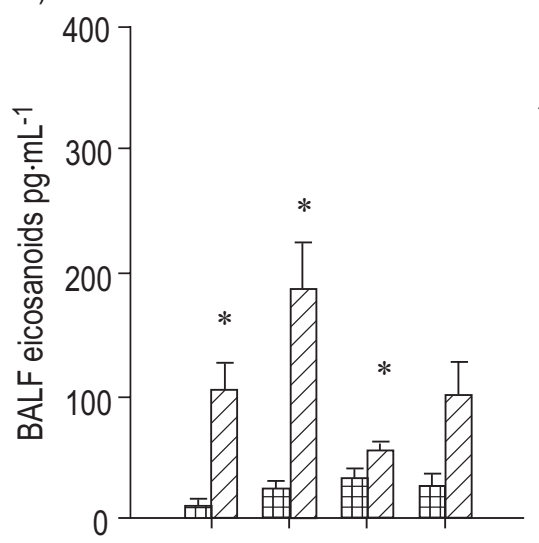

c)

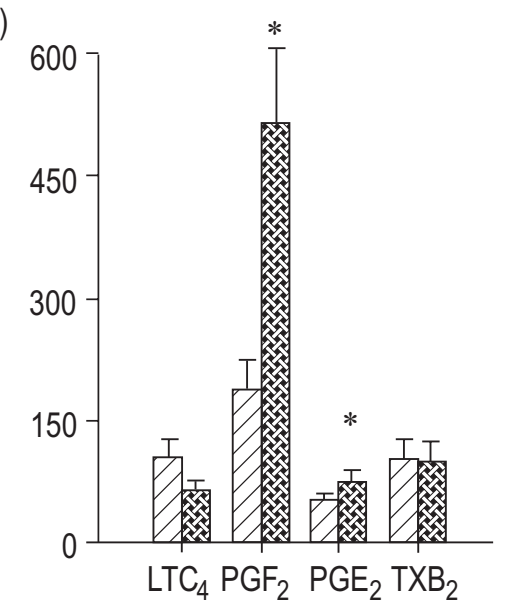

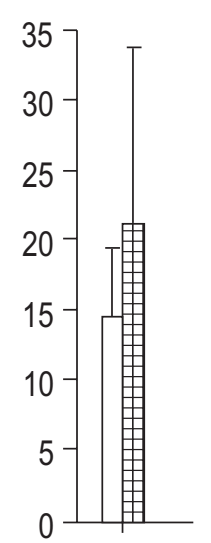
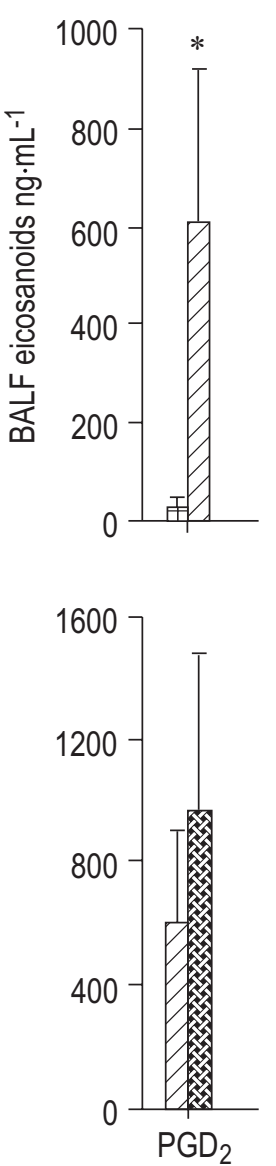

Fig. 5. - Bronchoalveolar lavage fluid (BALF) eicosanoid concentrations (mean \pm SEM) from: a) control $(\square ; n=6)$ and repeated wedge (曲; $\mathrm{n}=6) ; \mathrm{b})$ repeated wedge and repeated dry air challenge (DAC) (ש; $\mathrm{n}=10$ ); and c) repeated DAC and single DAC ( $\mathrm{x} ; \mathrm{n}=10)$ airways. LTC4: leukotriene $\mathrm{C} 4 ; \mathrm{PGF}_{2 \alpha}$ : prostaglandin $\mathrm{F}_{2 \alpha} ; \mathrm{PGE}_{2}$ : prostaglandin $\mathrm{E}_{2}$; $\mathrm{TXB}_{2}$ : thromboxane $\mathrm{B}_{2} ; \mathrm{PGD}_{2}$ : prostaglandin $\mathrm{D}_{2} .{ }^{*}: \mathrm{p}<0.05$, significantly different from graph pair.

The response to DAC, expressed as the peak $R$ pa after DAC, increased with repeated DAC (fig. 3a). The pattern of increase closely parallels that of baseline $R$ pa in the same airways (fig. 1), suggesting that the increased $R$ pa after DAC may merely reflect the increased baseline $R$ pa. Indeed, there was no significant increase in response to $\mathrm{DAC}$ when expressed as a change from baseline (fig. 3b).
Theoretically, a relative increase in baseline $R$ pa coupled with the same amount of smooth muscle shortening could result in an even greater response to an agonist due to the mathematical relationship between resistance and airway calibre. On the other hand, at least one study examining the relationship between baseline airway resistance and response to DAC found that two sequential challenges produced the same peak response, regardless of baseline [16]. Thus, based on the current data, it cannot be concluded that repetitive DAC enhances responsiveness to hyperpnoea with dry air.

Repeated DAC caused marked granulocytic inflammation of the airways (fig. 4). The magnitude of eosinophilia and neutrophilia in the BALF recovered from repeated DAC airways was much greater than that produced by a single DAC, both in this study (fig. 4c) and in previous studies [14]. Thus, it is unlikely that the DAC administered immediately before BAL in this study contributed to the granulocyte influx seen in figure 4 . It is also unlikely that the inflammation found in the repeated DAC airways is due simply to the high airflows generated during DAC, as previous studies have demonstrated that the same flow rate with conditioned air reduced the postchallenge changes in $R$ pa $[9,17]$ and tissue histology [17]. The neutrophil and eosinophil influx in the repeated DAC airways appears to be an exacerbation of the late phase response that follows a single DAC in dogs [11]. Thus, it is concluded that repeated DAC causes eosinophilic airway inflammation that persists for at least $24 \mathrm{~h}$ after the last DAC. In particular, the exaggerated DACinduced influx of eosinophils observed in this study is unique. Airway obstruction and eosinophilia are considered hallmarks of asthma in humans. The fact that these derangments can result from a stimulus analogous to that experienced by winter sport athletes is consistent with the hypothesis that repeated cold air hyperpnoea can produce asthma-like symptoms.

BALF obtained from repeated challenge airways contained increased concentrations of bronchoconstrictive mediators (fig. 5). Eicosanoid production plays an important role in the acute response to a single DAC in this dog model $[14,18,19]$ and in humans [20-23]. However, increased mediator production alone may not be responsible for the increased obstruction after DAC, as mediator concentrations in BALF from repeated DAC airways were lower than those found in BALF obtained after a single DAC (fig. 5c). The fact that the post-DAC BALF mediator concentrations are lower after repeated DAC (compared to a single DAC) suggests either decreased capacity for mediator production in airways repeatedly challenged with dry air, decreased airway sensitivity to the dry air stimulus, or a decrease in the effectiveness of the stimulus due to the protective effects of intraluminal mucus.

Granulocytes, macrophages, mast cells, and bronchial epithelial cells are potential sources of eicosanoid mediators in BALF [24]. It seems unlikely that neutrophils and eosinophils were responsible for the eicosanoid production measured after DAC because their concentration in BALF recovered from repeated DAC airways (fig. 4) increased in the face of decreased postchallenge mediator production (fig. 5). Macrophage and mast cell numbers in BALF recovered from single DAC and repeated DAC airways were not different, suggesting that differences in 
post-DAC eicosanoid concentrations were not attributable to differences in these cells. It is possible that there are fewer ciliated epithelial cells in the airways after repeated DAC, as epithelial repair after a single DAC requires $>24$ $\mathrm{h}$ to occur [25]. Thus, if the bronchial epithelium is the primary source of post-DAC eicosanoid production, then the reduced eicosanoid concentrations in a repeated DAC BALF (as compared to the BALF recovered after a single DAC) may reflect the accumulation of mucosal injury.

Post-DAC inflammation may be responsible for the increased baseline $R$ pa found in this study, as both neutrophils and eosinophils have been implicated in the development of airway obstruction. In a canine model of ozone-induced airway inflammation, neutrophil depletion blocked the development of airway obstruction [26]. This finding is not consistent in all studies, as others have reported dissociation between airway neutrophilia and airway obstruction $[13,27,28]$. On the other hand, eosinophils produce various cationic proteins that in other animal models produce airway obstruction through a variety of mechanisms [29]. Further study will be required to clarify the role of these cells in this model of hyperpnoeainduced airway inflammation and obstruction.

In summary, this study demonstrates that repeated dry air challenge of canine peripheral airways results in airway inflammation and progressive increases in baseline resistance. Because this model shares many similarities with cold-air hyperpnoea in humans, this study suggests that repeated episodes of cold air hyperpnoea cause airway injury and inflammation, and contributes to the development of airway obstruction. These data also support the hypothesis that repeated cold air hyperpnoea contributes to the development of asthma.

Acknowledgements. The authors thank S. McCulloch, T. Myers, and Y. Wang for their superb technical assistance.

\section{References}

1. Carlsen KH. Bronchial hyperreactivity in athletes. (in Norwegian). Nord Med 1994; 109: 16-18.

2. Larsson K, Ohlsén P, Larsson L, Malmberg P, Rydström $\mathrm{P}-\mathrm{O}$, Ulriksen $\mathrm{H}$. High prevalence of asthma in cross country skiers. BMJ 1993; 307: 1326-1329.

3. Mannix ET, Farber MO, Palange P, Galassetti P, Manfredi F. Exercise-induced asthma in figure skaters. Chest 1996; 109: 312-315.

4. Provost-Craig MA, Arbour KS, Sestili DC, Chabalko JJ, Ekinci E. The incidence of exercise induced bronchospasm in competitive figure skaters. J Asthma 1996; 33: 67-71.

5. Leuppi JD, Kuhn M, Comminot C, Reinhart WH. High prevelance of bronchial hyperresponsiveness and asthma in ice hockey players. Eur Respir J 1998; 12: 13-16.

6. Gilbert IA, Fouke JM, McFadden ER Jr. Intra-airway thermodynamics during exercise and hyperventilation in asthmatics. J Appl Physiol 1988; 64: 2167-2174.

7. Gilbert IA, Fouke JM, McFadden ER Jr. Heat and water flux in the intrathoracic airways and exercise-induced asthma. J Appl Physiol 1987; 63: 1681-1691.

8. McFadden ER Jr, Pichurko BM. Intraairway thermal profiles during exercise and hyperventilation in normal man. J Clin Invest 1985; 76: 1007-1010.

9. Freed AN, Bromberger-Barnea B, Menkes HA. Dry airinduced constriction in lung periphery: a canine model of exercise-induced asthma. $J$ Appl Physiol 1985; 59: 19861990.
10. Freed AN, Kelly U, Menkes HA. Airflow-induced bronchospasm: imbalance between airway cooling and airway drying. Am Rev Respir Dis 1987; 136: 595-599.

11. Freed AN, Adkinson NY Jr. Dry air-induced late phase responses in the canine lung periphery. Eur Respir J 1990; 3: 434-440.

12. Bierman CW, Spiro SG, Petheram I. Characterization of the late response in exercise-induced asthma. J Allergy Clin Immunol 1984; 74: 701-706.

13. Pliss LB, Ingenito EP, Ingrain RH, Pichurko B. Assessment of bronchoalveolar cell and mediator response to isocapnic hyperpnea in asthma. Am Rev Respir Dis 1990; 142: 73-78.

14. Omori C, Tagari P, Freed AN. Eicosanoids modulate hyperpnea-induced bronchoconstriction in canine peripheral airways. J Appl Physiol 1996; 81: 1255-1263.

15. Croxton TL, Lande B, Hirshman CA. Role of intracellular $\mathrm{pH}$ in relaxation of porcine tracheal smooth muscle by respiratory gases. Am J Physiol 1995; 268: L207-L213.

16. Freed AN. Regional and temporal variation in canine peripheral lung responses to dry air. J Appl Physiol 1989; 67: 1727-1733.

17. Freed AN, Omori C, Schofield BH, Mitzner W. Dry airinduced mucosal cell injury and bronchovascular leakage in canine peripheral airways. Am J Respir Cell Mol Biol 1994; 11: 724-732.

18. Freed AN, Wang D, Menkes HA. Dry-air induced constriction: effects of pharmacological intervention and temperature. J Appl Physiol 1987; 62: 1794-1800.

19. Freed AN, Peters SP, Menkes HA. Airflow-induced bronchoconstriction: role of epithelium and eicosanoid mediators. J Appl Physiol 1987; 62: 574-581.

20. O'Byrne PM, Jones GL. The effect of indomethacin on exercise-induced bronchoconstriction and refractoriness after exercise. Am Rev Respir Dis 1986; 134: 69-72.

21. Israel E, Dermarkarian R, Rosenberg M, et al. The effects of a 5-lipoxygenase inhibitor on asthma induced by cold, dry air. $N$ Engl J Med 1990; 323: 1740-1744.

22. Finnerty JP, Holgate ST. Evidence for the roles of histamine and prostaglandins as mediators in exerciseinduced asthma: the inhibitory effect of terfenadine and flurbiprofen alone and in combination. Eur Respir J 1990; 3: $540-547$.

23. Manning PJ, Richared MD, Watson M, et al. Inhibition of exercise-induced bronchoconstriction by MK-571, a potent leukotriene $\mathrm{D}_{4}$-receptor antagonist. $N$ Engl J Med 1990; 323: 1736-1739.

24. Carroll MP, Gratziou C, Holgate ST. Inflammation and inflammatory mediators in asthma. In: Clark TJH, Godfrey S, Lee TH, eds. Asthma. Chapman \& Hall Medical, 1992; pp. 182-231.

25. Omori C, Schofield BH, Mitzner W, Freed AN. Hyperpnea with dry air causes time-dependent alterations in mucosal morphology and bronchovascular permeability. $J$ Appl Physiol 1995; 78: 1043-1051.

26. O'Byrne PM, Walters EH, Gold BD, et al. Neutrophil depletion inhibits airway hyperresponsiveness induced by ozone exposure. Am Rev Respir Dis 1984; 130: 214-219.

27. O'Byrne PM, Walters EH, Aizawa H, Fabbri LM, Holtzman MJ, Nadel JA. Indomethacin inhibits the airway hyperresponsiveness but not the neutrophil influx induced by ozone in dogs. Am Rev Respir Dis 1984; 130: 220-224.

28. Crimi E, Balbo A, Milanese M, Miadonna A, Rossi GA, Brusasco V. Airway inflammation and occurrence of delayed bronchoconstriction in exercise-induced asthma. Am Rev Respir Dis 1992; 146: 507-512.

29. Coyle AJ, Uchida D, Ackerman SJ, Mitzner W, Irvin CG. Role of cationic proteins in the airway. Am J Respir Crit Care Med 1994; 150: S63-S71. 